\title{
Estimation of Salt Intake and its Relation to Knowledge and Attitude Regarding the Dangers of High Salt Intake among an Urban Omani Population A pilot study
}

Muhammad M. Shaikh, ${ }^{1}$ Ali H.Z. Alkhayari, ${ }^{1}$ Qusay A.K. Alabdulsalam, ${ }^{1}$ Khamis AlHashmi, ${ }^{2}$ Sunil K. Nadar ${ }^{1}$

ABSTRACT: Objectives: High salt consumption is a major risk factor for hypertension. Studies have shown dietary salt intake to be high in many parts of the world. This study aimed to assess the daily salt consumption of the Omani urban population and their knowledge and attitudes regarding dietary salt. Methods: This cross-sectional questionnairebased study was conducted in Muscat between September and December 2017. Participants were recruited from malls, university students and staff, hospital staff and their relatives and relatives of patients. A previously validated questionnaires were used to assess the participants' salt intake and their knowledge and attitudes regarding salt intake. Results: A total of 345 participants were included in this study (response rate: 69\%), of which 300 responses (mean age: $27.88 \pm 7.9$ years, $54.3 \%$ male) were included for analysis. Overall, $94.3 \%$ of the participants agreed that lowering salt in diet is important, and nearly half the participants said that they were taking measures to reduce salt intake. However, the median salt intake was high at $10.5 \mathrm{~g} /$ day (interquartile range: $7.3-15.1 \mathrm{~g} /$ day), with $90 \%$ of the respondents consuming more than the maximum recommended amount of salt per day. Salt intake was significantly higher in women and the older age group ( $>40$ years). There did not appear to be any correlation between awareness of the dangers of salt intake and the amount consumed. Conclusion: The salt intake in the sampled population in Oman was high and did not depend on knowledge. Strategies should be designed to reduce salt intake among the urban population, including health education to increase knowledge about the complications of high salt intake.

Keywords: Dietary Sodium Chloride; Knowledge, Attitudes and Practice; Oman.

\section{Advances IN KNOWLEDGe}

This study demonstrates that the average salt intake in the Omani population is high (more than double the recommended levels).

The knowledge regarding the dangers of high salt intake is high but this does not translate into action.

Application to Patient Care

Patients should be advised to reduce their salt intake.

Patients should be educated about the dangers of high salt in their diet and on different methods for reducing salt intake.

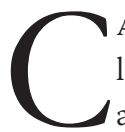

ardiovascular diseases (CVDs) are a leading cause of death and disability globally, affecting more than 17.5 million people annually. ${ }^{1}$ This is especially relevant in the Middle East region, which has seen dramatic transformations in its socio-economic situation over the last few decades, fuelled by rapid urbanisation, migration and modernisation and accompanied by significant changes to diet and lifestyle. This has led to an increase in the prevalence of cardiovascular risk factors such as diabetes, hypertension and obesity and a high incidence of CVDs. ${ }^{2-4}$ It is estimated that CVDs account for more than $34 \%$ of the deaths in the Middle East. $^{5}$

Hypertension is a major risk factor for CVD and disability and is now considered the number one risk factor attributable to burden of disease quantified by disability adjusted life years (DALYs) ${ }^{6}$ High salt intake is considered to be a major risk factor for hypertension; it is considered to be responsible for around one-third of the hypertension cases worldwide, which amounts to approximately 300 million people. ${ }^{7}$ In addition to hypertension, high salt intake is also found to be associated with Meniere's disease, osteoporosis and gastric and renal cell cancers. Modern Western diets, which are high in processed food, tend to have a high salt content and are considered a major global health issue. In fact, the World Health Organization (WHO) has listed the reduction of dietary salt intake by $30 \%$ as one of its nine global targets to be achieved by the year $2025 .^{8}$

As specified in the WHO recommendations, the ideal daily adult salt consumption should be $\leq 5 \mathrm{~g} /$ day. However, data from many countries have consistently shown that the dietary intake of salt far exceeds this amount. ${ }^{9}$ Many countries have implemented 
community education schemes to educate their population about the harms of high salt intake and the corresponding need to reduce the intake..$^{10-12}$

Dietary sources of sodium differ from one country and culture to another. For example, the top 10 sources in the USA are bread, pizza, sandwiches, cured meat, soup, burritos and tacos, savoury snacks, chicken, cheese and eggs and omelettes, while in some Asian countries, soup, rice and yeast bread account for almost a third of the dietary salt sources. ${ }^{13-15}$

In Oman, the prevalence of cardiovascular risk factors is high and it is expected that treatment for CVD will account for $21 \%$ of the healthcare budget by $2025 .{ }^{16}$ Hypertension is also fairly common, with a prevalence of $29.8 \%$ of the adult population. ${ }^{17}$ According to the national nutrition survey published in 2004, the average salt intake in the Omani population was approximately $11-12 \mathrm{~g} /$ day. ${ }^{18}$ Many steps have been taken to try to reduce this intake to recommended levels. ${ }^{19}$ These include a reduction in the salt content in bottled water and bread as well as public education. However, the effect of these steps is not yet evident.

This study aimed to assess the amount of salt intake by the urban population in Oman and compare it with the reported levels from 2004. In addition, this study sought to examine the urban population's knowledge and attitudes regarding salt and whether this has had any impact on their salt consumption.

\section{Methods}

This was a cross-sectional questionnaire-based study conducted among the urban population in Muscat, Oman, between September and December 2017. A convenience sampling method was used for this study. The subjects recruited included visitors to malls (during health promotional activities), university students and staff, hospital staff and their relatives and relatives of patients. Omani nationals aged above 18 years, who were normotensive and non-diabetic, had no evidence of CVD and were not taking any medications for hypertension, diabetes or CVD were included. Those below 18 years of age, who had hypertension, diabetes or evidence of CVD and those who were taking medications for any of these conditions were excluded.

The questionnaire had three parts. The first part comprised the demographic data of the participants including age, educational and employment status and eating habits. The second part of the questionnaire collected data on their knowledge, attitudes and practices regarding salt intake. This part was based on a questionnaire devised by WHO, which was translated into Arabic by a native professional Arabic speaker. ${ }^{20}$ It was then translated back into English to assess consistency. Subsequently, it was piloted on non-medical university students to verify whether any questions were confusing. The third part of the questionnaire was derived from a cross-sectional study conducted in South Africa. ${ }^{21}$ This questionnaire was selected, as the dietary habits of South Africans are fairly similar to that of Omanis. In addition, this questionnaire has been validated and the details are published. ${ }^{21}$ However, a few changes were made to the questionnaire by deleting some of the food items that are not consumed in Oman and substituting them with similar food types. This questionnaire was also translated into Arabic and then back-translated into English to assess consistency. This questionnaire is free-to-use and does not require any licence to be used. However, permission was obtained from the authors of the questionnaire prior to the study.

Based on the responses to the questionnaire, the daily salt intake of every participant was calculated according to the formula devised by Charlton et al. ${ }^{21}$ This was calculated by multiplying the average of the chosen frequency with the sodium $(\mathrm{Na})$ content per serving. The sum of the 36 categories would then give the total $\mathrm{Na}$ intake (mg/day) of a participant. Conversion of $\mathrm{Na}$ (mg/day) to salt (g/day) was obtained by dividing the amount by 1,000 and then multiplying it by 2.5 . The equation applied was:

$\mathrm{S}(\mathrm{g} / \mathrm{d})=\left[\left(\mathrm{f}_{\mathrm{n} 1} \times \mathrm{Na}_{\mathrm{n} 1}\right)+\left(\mathrm{f}_{\mathrm{n} 2} \times \mathrm{Na}_{\mathrm{n} 2}\right)+\left(\mathrm{f}_{\mathrm{n} 36}+\mathrm{Na}_{\mathrm{n} 36}\right)\right] \times 2.5 / 1000$ [Equation 1]

where $\mathrm{S}(\mathrm{g} / \mathrm{d})$ is the daily salt in grams per day, $\mathrm{fn}$ is the chosen frequency of the food category ' $n$ ' and Nan is the sodium in one serving of the food category ' $n$ '.

The sample size was calculated based on the formula for calculating the number required for a cross-sectional prevalence study. The sample size was:

$$
\mathrm{n}=\left(\mathrm{Z}_{1-\alpha / 2}\right)^{2}(\sigma)^{2} / \mathrm{d}^{2} \quad \text { [Equation 2] }
$$

where $(Z 1-\alpha / 2)$ is the standardised value for the corresponding level of confidence, which is 2.58 for a 99\% confidence interval or a $1 \%$ type I error, $\sigma$ is the standard deviation based on previous studies (a value of $5 \mathrm{~g}$ was used for the present calculations), and $\mathrm{d}$ is the margin of error (set at $1 \mathrm{~g}) .{ }^{9}$ Using these values, a sample size of 166 was derived.

The data were analysed using the Statistical Package for the Social Sciences (SPSS), Version 21 (IBM Corp., Chicago, Illinois, USA). All data are described as either percentages or mean \pm standard deviation or median (interquartile range [IQR]). The chi-square test, student's t-test or non-parametric tests (Mann-Whitney U test or Kruskall-Wallis test) 
Table 1: Charactertistics of the included participants $(\mathrm{N}=300)$

\begin{tabular}{lc} 
Characteristic & $\mathbf{n}(\%)$ \\
Age in years & \\
$18-28$ & $146(48.7)$ \\
$29-39$ & $102(34.0)$ \\
$\geq 40$ & $52(17.3)$ \\
Mean \pm SD & $27.88 \pm 7.9$ \\
Gender & \\
Male & $163(54.3)$ \\
Female & $137(45.7)$ \\
Educational level & \\
Primary school or below & $23(7.7)$ \\
Secondary school & $115(38.3)$ \\
Diploma & $42(14.0)$ \\
Bachelor's degree & $114(38.0)$ \\
Master's degree/PhD or higher & $6(2.0)$ \\
Employment Status & \\
Employed & $136(45.3)$ \\
Student & $126(42.0)$ \\
Retired/unemployed & $38(12.7)$ \\
SD standard deviation; PhD = doctor of philosophy. & \\
\hline
\end{tabular}

were used as appropriate. Spearman's coefficient of correlation was used to assess the correlation between salt intake (non-normally distributed data) and age. A $P$ value of $<0.05$ was considered to be significant.

Ethical approval was granted by the Medical Research Ethics Committee, College of Medicine and Health Sciences at Sultan Qaboos University, Muscat, Oman. Before the participants began filling in the questionnaire, the rationale and reason for conducting the study were explained and they were required to sign a consent statement on the questionnaire.

\section{Results}

A total of 345 responses were received (response rate: 69\%). However, 45 responses were excluded from the study as they were incompletely filled. Therefore, responses obtained from 300 participants (mean age: $27.88 \pm 7.9$ years, range: $18-56)$ of which the majority were male $(54.3 \%)$ were included in the final analysis. All the participants were residents of Muscat. A total of $46 \%$ of the participants had a secondary school degree or a lower qualification, and more than half (54.7\%) of the participants were not in active employment (i.e. either a student, unemployed or retired) [Table 1].
Table 2: Responses to attitude, knowledge and practice questions $(\mathrm{N}=300)$

$\begin{array}{lc}\text { Parameter } & \text { n (\%) } \\ \text { Attitude towards salt intake } & \\ \text { How important is it to lower the salt/sodium in your diet? } \\ \text { Not at all important } & 17(5.7) \\ \text { Somewhat important } & 165(55.0) \\ \text { Very important } & 118(39.3) \\ \text { What is your opinion regarding the amount of salt you } \\ \text { consume? } \\ \text { Too low/low } \\ \text { Just right } \\ \text { High/Too high } & 42(14.0) \\ \text { Don't know } & 196(65.3) \\ \text { Behaviour related to salt intake } & 40(13.3) \\ \text { Do you add salt to food at the table? } & 22(7.3) \\ \text { Never/rarely } & \\ \text { Sometimes } & 127(42.3) \\ \text { Often/always } & 81(27.0) \\ \text { Do you add salt while cooking? } & 92(30.7) \\ \text { Never/sometimes } & 33(11.0) \\ \text { Mostly/always } & 267(89.0)\end{array}$

Do you routinely check the salt content on food labels before purchasing them?

Yes

No

Do you take any steps on a regular basis to control your salt intake?

Yes

No

Don't know

Knowledge related to salt intake

Do you think that a high salt diet can cause serious health problems?

Yes

$268(89.3)$

No

Don't know

Can high salt intake cause the following diseases?

$\begin{array}{ll}\text { Hypertension } & 214(71.3) \\ \text { Kidney stones } & 48(16.0) \\ \text { Osteoporosis } & 5(1.7) \\ \text { All of the above } & 33(11.0)\end{array}$

Do you know the recommended maximum salt intake per person per day?

Yes

No $277(92.3)$ 
Table 3: Differences among the groups with normal and high salt intake $(\mathrm{N}=300)$

\begin{tabular}{|c|c|c|c|c|}
\hline \multirow[t]{2}{*}{ Variable } & \multirow[t]{2}{*}{ Total } & \multicolumn{2}{|c|}{ n (\%) } & \multirow{2}{*}{$\begin{array}{c}P \\
\text { value }\end{array}$} \\
\hline & & $\begin{array}{c}\text { Normal } \\
\text { salt intake } \\
(\mathbf{n}=30)\end{array}$ & $\begin{array}{l}\text { High salt } \\
\text { intake } \\
(n=270)\end{array}$ & \\
\hline \multicolumn{2}{|c|}{$\begin{array}{l}\text { Mean age } \pm \mathrm{SD} \text { in } \\
\text { years }\end{array}$} & $24.5 \pm 6.7$ & $28.2 \pm 7.9$ & $0.1^{*}$ \\
\hline \multicolumn{2}{|l|}{ Gender } & & & $0.02^{+}$ \\
\hline Male & 163 & $25(15.3)$ & 138 (84.7\%) & \\
\hline Female & 137 & $5(4.4)$ & $132(95.6 \%)$ & \\
\hline \multicolumn{2}{|c|}{ Employment status } & & & $0.03^{+}$ \\
\hline Employed & 136 & $8(5.9)$ & $128(94.1)$ & \\
\hline $\begin{array}{l}\text { Student/ } \\
\text { retired/ } \\
\text { unemployed }\end{array}$ & 164 & $22(13.4)$ & $142(86.6)$ & \\
\hline \multicolumn{2}{|c|}{ Educational level } & & & $0.002^{+}$ \\
\hline $\begin{array}{l}\text { Secondary } \\
\text { school or } \\
\text { below }\end{array}$ & 138 & $25(18.1)$ & 113 (81.9) & \\
\hline $\begin{array}{l}\text { Diploma or } \\
\text { higher }\end{array}$ & 162 & $5(3.7)$ & $157(96.3)$ & \\
\hline \multicolumn{4}{|c|}{ Actively takes steps to reduce salt intake } & $0.43^{+}$ \\
\hline Yes & 129 & $10(7.8)$ & $121(92.3)$ & \\
\hline No & 151 & $16(10.6)$ & 133 (89.5) & \\
\hline Don't know & 20 & $4(20.0)$ & $16(80.0)$ & \\
\hline \multicolumn{4}{|c|}{ Aware of the dangers of high salt intake } & $0.41^{+}$ \\
\hline Yes & 268 & $28(10.4)$ & $240(89.6)$ & \\
\hline $\begin{array}{l}\text { No/don't } \\
\text { know }\end{array}$ & 32 & $2(6.3)$ & 30 (93.8) & \\
\hline
\end{tabular}

More than half of the participants (55.0\%) agreed that lowering the salt/ $\mathrm{Na}$ in their diet is somewhat important. Almost half of the participants (42.3\%) remarked that they never or rarely added salt to their food at the table. Nearly half of the participants said they tried to control their salt consumption on a regular basis (43\%). A total of $79.3 \%$ of the respondents felt that they were consuming either just the right amount of salt (65.3\%) or lower than the recommended level (14.0\%). Most (89.3\%) believed that a high salt diet causes serious health diseases. Most of the participants (92.3\%) did not know the recommended daily salt intake per person per day. While many (71.3\%) believed that excessive salt consumption can cause hypertension, not many were aware of the other conditions that can be caused by excess salt; $16.0 \%$ stated that it causes kidney stones, $1.7 \%$ stated that it
Table 4: Comparison of median salt intake across different groups

\begin{tabular}{|c|c|c|}
\hline Group & $\begin{array}{c}\text { Salt intake in g/day } \\
\text { (IQR) }\end{array}$ & $P$ value \\
\hline Age group in years & & $0.01^{*}$ \\
\hline$\geq 40$ & $11.8(9.5-13.4)$ & \\
\hline $30-39$ & $10.6(7.6-15.8)$ & \\
\hline $18-29$ & $10.3(7.12-15.2)$ & \\
\hline Gender & & $0.03^{+}$ \\
\hline Male & $9.9(6.1-14.4)$ & \\
\hline Female & $11.1(7.9-15.6)$ & \\
\hline Educational status & & $0.4^{+}$ \\
\hline $\begin{array}{l}\text { Secondary school or } \\
\text { below }\end{array}$ & $10.02(6.1-15.2)$ & \\
\hline Diploma or higher & $10.6(7.6-15.4)$ & \\
\hline Employment status & & $0.8^{\dagger}$ \\
\hline Employed & $10.4(7.1-14.6)$ & \\
\hline Unemployed & $10.7(7.8-14.9)$ & \\
\hline
\end{tabular}

causes osteoporosis and $11.0 \%$ thought that it causes all the conditions listed [Table 2].

When investigating the factors that contributed to the knowledge regarding salt, it was found that $67 \%$ of participants with a master's/PhD degree and $44.0 \%$ with a bachelor's degree thought that lowering salt consumption was very important, while only $27.5 \%$ of high school diploma holders or those with a lower qualification thought it was very important to lower salt intake $(P=0.02)$. Similarly, $71.3 \%$ of those above 40 years of age said they take actions to control salt consumption compared to $43.5 \%$ of participants below the age of $40(P=0.005)$.

The median salt intake in the present cohort was $10.5 \mathrm{~g} /$ day (IQR: 7.3-15.1 g/day). Out of the 300 participants, the salt intake of 270 (90.0\%) participants was more than the WHO recommended amount of 5 $\mathrm{g} /$ day, while only 30 (10.0\%) had an intake of $\leq 5 \mathrm{~g} /$ day. More males (73.3\%), those with a secondary school qualification or below (70.0\%) and those who were unemployed (73.3\%) had normal salt intake compared to women (26.6\%), those who had a diploma degree or higher qualification (30\%) and those in active employment (26.7\%) [Table 3].

The calculated median salt intake by males was 9.9 g/day (IQR: 6.1-14.4 g/day) compared to $11.1 \mathrm{~g} /$ day (IQR: $7.9-15.6 \mathrm{~g} /$ day) by females $(P=0.03)$. A total of $86.3 \%$ of male participants had salt intake more 
than the WHO-recommended amount ( $\geq 5 \mathrm{~g} /$ day) compared to $94.3 \%$ of female participants [Table 4].

Analysis based on age groups (18-29, 30-39 and $\geq 40$ years) revealed that the salt intake was the highest in the older age group ( $\geq 40$ years) at $11.8 \mathrm{~g} /$ day (IQR: 9.5-13.4 g/day), and the lowest intake was in the youngest group (18-29 years) at $10.3 \mathrm{~g} /$ day (IQR: 7.12-15.2 g/day; $P=0.01$ ). However, there was no overall correlation between age and the amount of salt consumed (Spearman's coefficient of correlation = $0.06 ; P=0.27$ ).

There was no difference in salt intake between the unemployed and employed groups (10.7 versus $10.4 \mathrm{~g} /$ day; $P=0.8$ ). There was also no significant difference between those with a secondary school education or below and those with a diploma or higher qulaifications (10.02 versus $10.6 \mathrm{~g} /$ day; $P=0.4$ ).

The top three food items contributing the most to salt intake in the sample are, in order, fish biltong (dried salty fish), white bread and soup. The averages of sodium intake in fish biltong, white bread and soup are $469.1 \mathrm{mg} /$ day, $386.8 \mathrm{mg} /$ day and $370.4 \mathrm{mg} /$ day, respectively.

\section{Discussion}

This study assessed the amount of dietary salt intake in Oman among a healthy population and correlated it with their awareness of the dangers of high salt intake. Due to the widespread use of sodium in food processing, extensive distribution of sodium in food, presence of sodium in drinking water and extensive use of table salt, the accurate measurement of salt intake is difficult.

The present study found that the median daily salt intake was $10.5 \mathrm{~g} /$ day (IQR: 7.3-15.1 g/day), which is consistent with the findings of previous reports and studies from other countries in the Arabian Gulf region. ${ }^{19,22}$ The median salt intake of women in the present study was higher than that of men. This is contrary to many other studies that found the salt intake in men to be more than in women. ${ }^{23,24}$ However, a few studies have shown that women consume more salt than men, such as in Japan, while some studies have found no difference between the two genders..$^{25,26}$ These different results could be because of cultural differences among the different populations or indeed the method used to assess salt intake. Eating habits between the genders can vary considerably according to the culture. In some cultures, men tend to eat out more, while women stay at home and tend to eat more home-cooked meals. ${ }^{26}$

Awareness regarding the dangers of salt intake was high in the present study, an observation reflected in other recent studies from the region. ${ }^{22,27}$ However, this awareness did not translate into actual reductions in the amount of salt consumed. The present study found that the youngest age group (18-28 years) had the lowest salt intake compared to the other two groups, although based on the dietary practices noted in the questionnaire, they were less likely than the older group to take actions to reduce their salt intake. Similarly, it was found that participants with a diploma degree or higher qualification claimed to take actions to reduce salt intake, but there was no difference in the amount of salt consumed. Though some studies have shown that salt consumption decreases with increasing educational status, most studies show that education or awareness itself is inadequate in reducing salt intake. ${ }^{28,29}$ Similarly, the employed participants tended to have a slightly higher salt intake compared to the unemployed participants. This could be a reflection of the busy lifestyle of the employed participants, who would have had to eat outside, while those at home probably had more home-cooked meals.

The current study found that the major food items that contribute to high salt intake are fish biltong, bread and soup. The major processed food items contributing to salt intake vary among populations. For example, in Kuwait, the major food items contributing to salt intake are Kuwaiti composite dishes, bread and sandwiches and pastries, while in the Netherlands, the major sources are bread and cereal products, cheese and meat. ${ }^{19,30}$

One of the main issues that hinders the reduction of salt intake by the public is their perception of the recommended salt levels and high salt intake. This study found that although almost none of the respondents knew the recommended level of dietary salt intake, most still felt that they were consuming just the right amount of salt or indeed even less, while in reality, they were consuming a high amount of salt. Even those who claimed to take steps to reduce their salt intake were consuming a high amount. It is imperative to increase awareness of the presence of high levels of salt in processed food and in other routinely consumed foodstuffs. Increasing awareness regarding normal or high dietary salt intake and the importance of avoiding food with high salt content is key to tackling the problem of high dietary salt intake. ${ }^{9,11,12}$

The major limitation of the present study was the lack of urinary sodium estimation to validate the responses of the individuals, making the findings unreliable. However, the questionnaire that was used was previously validated. ${ }^{21}$ Being a questionnairebased study, one of the inherent limitations is that patients tend to respond based on what they feel they 
should be doing rather than what they are actually doing. ${ }^{31}$ Hence, the amount of salt consumed might be even higher than the amount obtained via the questionnaire. However, this was a pilot study, and its intention was to obtain a general sense for the amount of salt consumption in the country. Another limitations, was that the sample size was small, which would affect the generalisability of the study's findings. In addition, this survey was limited to the Muscat region, which is urban, and did not take into consideration the vast geographical extent of Oman. It is highly likely that in rural parts of the country, where the diet is mainly composed of freshly cooked food, the salt content would vary significantly. Another limitation is that the questionnaire contained only 36 food categories with $50 \mathrm{mg} \mathrm{Na}$ /serving or more; many food items that have less than $50 \mathrm{mg} \mathrm{Na}$ /serving were not included in the questionnaire. Therefore, it is likely that the actual salt intake might be higher than the calculated amount. Lastly, another possible limitation is that the questionnaire was established with the referenced sodium amount for each serving according to South African food. The Omani food and serving size may contain different amounts of sodium, but a reference for the sodium content in Omani food was not available. Even though it is not possible to categorically state that the salt intake calculated in the present study is accurate, it provides a general idea of the salt intake among the urban population of Oman. The present study, along with other similar studies from the region, will help shape future public health initiatives to tackle the problem of high dietary salt.

\section{Conclusion}

Despite many health education campaigns and public awareness programmes, the level of salt consumption was high among the small sample of this study. The high level of awareness did not translate into action. Further education of the public is necessary to help people reduce the amount of salt in their diet. Additionally, food manufacturers could be required to reduce the amount of salt in commercially available food.

\section{AUTHORS' CONTRIBUTION}

MMS was involved in data collection and manuscript writing. AHZA and QAKA were involved in data collection. KA contributed to manuscript writing. SKN was involved in data analysis and manuscript writing. All authors approved the final version of the manuscript.

\section{CONFLICT OF INTEREST}

The authors declare no conflicts of interest.

\section{FUNDING}

No funding was received for this study.

\section{References}

1. Roth GA, Johnson C, Abajobir A, Abd-Allah F, Abera SF, Abyu G, et al. Global, regional, and national burden of cardiovascular diseases for 10 causes, 1990 to 2015. J Am Coll Cardiol 2017; 70:1-25. https://doi.org/10.1016/j.jacc.2017.04.052.

2. Traina MI, Almahmeed W, Edris A, Murat Tuzcu E. Coronary heart disease in the Middle East and North Africa: Current status and future goals. Curr Atheroscler Rep 2017; 19:24. https://doi.org/10.1007/s11883-017-0659-9.

3. Alhabib KF, Batais MA, Almigbal TH, Alshamiri MQ, Altaradi $\mathrm{H}$, Rangarajan S, et al. Demographic, behavioral, and cardiovascular disease risk factors in the Saudi population: Results from the Prospective Urban Rural Epidemiology study (PURE-Saudi). BMC Public Health 2020; 20:1213. https://doi.org/10.1186/s12 889-020-09298-w.

4. Shehab A, Bhagavathula AS, Alhabib KF, Ullah A, Suwaidi JA, Almahmeed W, et al. Age-related sex differences in clinical presentation, management, and outcomes in ST-segment-elevation myocardial infarction: Pooled analysis of 15532 patients from 7 Arabian Gulf registries. J Am Heart Assoc 2020; 9:e013880. https://doi.org/10.1161/JAHA.119.013880.

5. Bhagavathula AS, Shehab A, Ullah A, Rahmani J. The burden of cardiovascular disease risk factors in the Middle East: A systematic review and meta-analysis focusing on primary prevention. Curr Vasc Pharmacol 2021; 19:379-89. https://doi.org/10.2174 /1573406416666200611104143.

6. Bromfield S, Muntner P. High blood pressure: The leading global burden of disease risk factor and the need for worldwide prevention programs. Curr Hypertens Rep 2013; 15:134-6. https://doi.org/10.1007/s11906-013-0340-9.

7. Aaron KJ, Sanders PW. Role of dietary salt and potassium intake in cardiovascular health and disease: A review of the evidence. Mayo Clin Proc 2013; 88:987-95. https://doi.org/10.1016/j. mayocp.2013.06.005.

8. World Health Organisation. Salt reduction. From: http:// www.who.int/news-room/fact-sheets/detail/salt-reduction Accessed: Aug 2021

9. Powles J, Fahimi S, Micha R, Khatibzadeh S, Shi P, Ezzati M, et al. Global, regional and national sodium intakes in 1990 and 2010: A systematic analysis of $24 \mathrm{~h}$ urinary sodium excretion and dietary surveys worldwide. BMJ Open 2013; 3:e003733. https://doi.org/10.1136/bmjopen-2013-003733.

10. Farrand C, He FJ, MacGregor GA. Reducing population salt intake in the Eastern Mediterranean Region - Time for urgent action. East Mediterr Health J 2015; 20:761-4. https://doi.org/10.2 $6719 / 2014.20 .12 .761$

11. He FJ, MacGregor GA. A comprehensive review on salt and health and current experience of worldwide salt reduction programmes. J Hum Hypertens 2009; 23:363-84. https://doi. org/10.1038/jhh.2008.144.

12. MacGregor GA, He FJ. World action on salt. Lancet 2008; 371:471. https://doi.org/10.1016/S0140-6736(08)60228-7.

13. U.S. Department of Health and Human Services, U.S. Department of Agriculture. What we eat in America. From: https://www.ars.usda.gov/ARSUserFiles/80400530/pdf/ DBrief/sodium_intake_0708.pdf Accessed: Aug 2021. 
14. Batcagan-Abueg AP, Lee JJ, Chan P, Rebello SA, Amarra MS. Salt intakes and salt reduction initiatives in Southeast Asia: A review. Asia Pac J Clin Nutr 2013; 22:490-504. https://doi. org/10.6133/apjen.2013.22.4.04.

15. Firestone MJ, Beasley JM, Kwon SC, Ahn J, Trinh-Shevrin C, Yi SS. Asian American dietary sources of sodium and salt behaviors compared with other racial/ethnic groups, NHANES, 2011-2012. Ethn Dis 2017; 27:241-8. https://doi.org/10.18865/ ed.27.3.241.

16. Al Riyami A, Elaty MA, Morsi M, Al Kharusi H, Al Shukaily W, Jaju S. Oman world health survey: Part 1 - methodology, sociodemographic profile and epidemiology of non-communicable diseases in Oman. Oman Med J 2012; 27:425-43. https://doi. org/10.5001/omj.2012.43

17. Nadar SK, Al-Riyami H, Al-Riyami A, Al-Lawati H, Panakkal B, Mohammed S, et al. May measurement month 2018; An analysis of blood pressure screening results from Oman. Eur Heart J Suppl 2020; 22:H100-3. https://doi.org/10.1093/eurheartj/suaa039.

18. Centers for Disease Control and Prevention (CDC), Ministry of Health (Oman), United Nations Children's Fund (UNICEF), World Health Organization Regional Office for the Eastern Mediterranean (EMRO-WHO). Oman food fortification study 2004. From: http://ghdx.healthdata.org/record/oman-food-for tification-study-2004 Accessed: Aug 2021

19. Alhamad N, Almalt E, Alamir N, Subhakaran M. An overview of salt intake reduction efforts in the Gulf Cooperation Council countries. Cardiovasc Diagn Ther 2015; 5:172-7. https://doi. org/10.3978/j.issn.2223-3652.2015.04.06

20. WHO attitudes and behaviour towards salt intake 2018. From: http://www.who.int/ncds/surveillance/steps/riskfactor/ STEPS_SaltModule.pdf Accessed: Aug 2021.

21. Charlton KE, Steyn K, Levitt NS, Jonathan D, Zulu JV, Nel JH. Development and validation of a short questionnaire to assess sodium intake. Public Health Nutr 2008; 11:83-94. https://doi. org/10.1017/S1368980007000146.

22. Al-Mawali A, D'Elia L, Jayapal SK, Morsi M, Al-Shekaili WN, Pinto AD, et al. National survey to estimate sodium and potassium intake and knowledge attitudes and behaviours towards salt consumption of adults in the Sultanate of Oman. BMJ Open 2020; 10:e037012. https://doi.org/10.1136/bmjopen-2020-037012.
23. Rezaei S, Mahmoudi Z, Sheidaei A, Aryan Z, Mahmoudi N, Gohari K, et al. Salt intake among Iranian population: The first national report on salt intake in Iran. J Hypertens 2018; 36:2380-9. https://doi.org/10.1097/HJH.0000000000001836.

24. Brown IJ, Tzoulaki I, Candeias V, Elliott P. Salt intakes around the world: Implications for public health. Int J Epidemiol 2009; 38:791-813. https://doi.org/10.1093/ije/dyp139.

25. Sasaki S, Yanagibori R, Amano K. Validity of a self-administered diet history questionnaire for assessment of sodium and potassium: Comparison with single 24-hour urinary excretion. Jpn Circ J 1998; 62:431-5. https://doi.org/10.1253/jcj.62.431.

26. Hipgrave DB, Chang S, Li X, Wu Y. Salt and sodium intake in China. JAMA 2016; 315:703-5. https://doi.org/10.1001/jama.20 15.15816.

27. Al-Riyami H, Al-Abdulsalam Q, Al-Khayari L, Al-Mushrafi H, Al-Alawi Z, Al-Hashmi K, et al. Awareness of the dangers of high salt intake among the urban Omani population. Sultan Qaboos Univ Med J 2020; 20:e352-6. https://doi.org/10.18295/ squmj.2020.20.03.016.

28. Nestle M, Wing R, Birch L, DiSogra L, Drewnowski A, Middleton S, et al. Behavioral and social influences on food choice. Nutr Rev 1998; 56:S50-64. https://doi.org/10.1111/j.1753-4887.1998.tb01732.x.

29. Wang X, Li X, Vaartjes I, Neal B, Bots ML, Hoes AW, et al. Does education level affect the efficacy of a community based salt reduction program? - A post-hoc analysis of the China Rural Health Initiative Sodium Reduction Study (CRHI-SRS). BMC Public Health 2016; 16:759. https://doi.org/10.1186/s12889016-3454-6.

30. Temme EHM, Hendriksen MAH, Milder IEJ, Toxopeus IB, Westenbrink S, Brants HAM, et al. Salt reductions in some foods in the Netherlands: Monitoring of food composition and salt intake. Nutrients 2017; 9:791. https://doi.org/10.3390/ nu9070791.

31. Safdar N, Abbo LM, Knobloch MJ, Seo SK. Research methods in healthcare epidemiology: Survey and qualitative research. Infect Control Hosp Epidemiol 2016; 37:1272-7. https://doi. org/10.1017/ice.2016.171 